Portland State University

PDXScholar

5-7-2018

\title{
Transient Reactivation of a Deep-Seated Landslide by Undrained Loading Captured With Repeat Airborne and Terrestrial Lidar
}

\author{
Adam M. Booth \\ Portland State University, boothad@pdx.edu \\ Justin McCarley \\ Portland State Univeristy \\ Jason Hinkle \\ Weyerhaeuser Company \\ Jean-Paul Ampuero \\ California Institute of Technology \\ Michael P. Lamb \\ California Institute of Technology
}

Follow this and additional works at: https://pdxscholar.library.pdx.edu/geology_fac

Part of the Geology Commons

Let us know how access to this document benefits you.

\section{Citation Details}

Booth, A. M., McCarley, J., Hinkle, J., Shaw, S., Ampuero, J.-P., \& Lamb, M. P. (2018). Transient reactivation of a deepseated landslide by undrained loading captured with repeat airborne and terrestrial lidar. Geophysical Research Letters, 45.

This Article is brought to you for free and open access. It has been accepted for inclusion in Geology Faculty Publications and Presentations by an authorized administrator of PDXScholar. Please contact us if we can make this document more accessible: pdxscholar@pdx.edu. 


\section{Geophysical Research Letters}

\section{RESEARCH LETTER \\ 10.1029/2018GL077812 \\ Key Points: \\ - Image correlation of airborne lidar documents 3-D, 1-m resolution landslide surface displacement field \\ - Undrained loading transiently reactivated $2-\mathrm{km}$ long landslide, and slip surface strengthening of $\sim 1 \mathrm{kPa}$ inhibited further acceleration \\ - Landslide motion is controlled by internal mass redistribution and insensitive to external environmental forcing}

Supporting Information:

- Supporting Information S1

Correspondence to:

A. M. Booth,

boothad@pdx.edu

\section{Citation:}

Booth, A. M., McCarley, J., Hinkle, J., Shaw, S., Ampuero, J.-P., \& Lamb, M. P. (2018). Transient reactivation of a deep seated landslide by undrained loading captured with repeat airborne and terrestrial lidar. Geophysical Research Letters, 45. https://doi.org/10.1029/ 2018GL077812

Received 6 MAR 2018 Accepted 29 APR 2018 Accepted article online 7 MAY 2018

C2018. American Geophysical Union. All Rights Reserved.

\section{Transient Reactivation of a Deep-Seated Landslide by Undrained Loading Captured With Repeat Airborne and Terrestrial Lidar}

\author{
Adam M. Booth ${ }^{1}$ iD, Justin McCarley ${ }^{1}$, Jason Hinkle ${ }^{2}$ iD, Susan Shaw ${ }^{2}$, Jean-Paul Ampuero ${ }^{3,4}$ iD, \\ and Michael P. Lamb \\ ${ }^{1}$ Department of Geology, Portland State University, Portland, OR, USA, ${ }^{2}$ Weyerhaeuser Company, Springfield, OR, USA, \\ ${ }^{3}$ Division of Geological and Planetary Sciences, California Institute of Technology, Pasadena, CA, USA, ${ }^{4}$ Université Côte \\ d'Azur, IRD, CNRS, Observatoire de la Côte d'Azur, Géoazur, Valbonne, France
}

Abstract Landslides reactivate due to external environmental forcing or internal mass redistribution, but the process is rarely documented quantitatively. We capture the three-dimensional, 1-m resolution surface deformation field of a transiently reactivated landslide with image correlation of repeat airborne lidar. Undrained loading by two debris flows in the landslide's head, rather than external forcing, triggered reactivation. After that loading, the lower $2 \mathrm{~km}$ of the landslide advanced by up to $14 \mathrm{~m}$ in 2 years before completely stopping. The displacement field over those 2 years implies that the slip surface gained $1 \mathrm{kPa}$ of shear strength, which was likely accomplished by a negative dilatancy-pore pressure feedback as material deformed around basal roughness elements. Thus, landslide motion can be decoupled from external environmental forcing in cases, motivating the need to better understand internal perturbations to the stress field to predict hazards and sediment fluxes as landscapes evolve.

Plain Language Summary Landslides can creep slowly for years and damage infrastructure, or they can suddenly fail catastrophically and endanger lives. Understanding the mechanisms that control these diverse movement patterns is therefore essential to manage hazards and to estimate long-term erosion rates due to landsliding. We used new 3-D topographic data to measure the detailed movement patterns of a landslide in the Oregon Cascades that exhibited both catastrophic and creeping motion. Catastrophic failure at the top of the landslide pushed the lower part of the landslide to begin creeping, but it did not fail catastrophically. Instead, that part of the landslide strengthened as it slipped and prevented further catastrophic failure. This movement pattern occurred during an exceptionally dry period, which suggests that precipitation data may not be sufficient to predict the type of landslide and when a landslide will occur at a particular location.

\section{Introduction}

Large, slow-moving landslides can be the dominant hillslope process in landscapes underlain by weak lithologies (Kelsey, 1978; Mackey \& Roering, 2011; Scheingross et al., 2013). The velocities of such landslides are thought to be coupled to changes in environmental conditions that affect subsurface pore pressures over a wide range of timescales (Bennett et al., 2016; Bovis \& Jones, 1992; Iverson \& Major, 1987; Schulz, Kean, \& Wang, 2009). Perturbations to the landslide's stress field from the addition, removal, or redistribution of mass within the landslide can also change driving and resisting stresses and influence movement rates (Allison \& Brunsden, 1990; Hutchinson \& Bhandari, 1971; Massey et al., 2013). When they are actively deforming, landslides can deliver sediment to channels at rates that far exceed long-term, catchment-averaged erosion rates, suggesting that they are dormant much of the time (DeLong et al., 2012; Mackey \& Roering, 2011). Understanding the mechanics of landslide reactivation is essential for discerning their role in landscape evolution and evaluating the hazards they generate, but observational limitations have made it challenging to document that process at high spatial and temporal resolution.

Repeat high-resolution topography from lidar or photogrammetry offers an unprecedented opportunity to measure topographic changes caused by surface processes, especially landslides (Daehne \& Corsini, 2013). Traditional ground-based landslide monitoring techniques, including manual surveys, differential Global Positioning System measurements, and instrumentation of boreholes, offer precise measurements at specific locations but are limited in spatial coverage. Remote sensing techniques such as interferometric synthetic- 
aperture radar can improve spatial coverage but have until recently rarely been used to resolve deformation in more than the line-of-sight direction (Delbridge et al., 2016; Hu et al., 2014; Raucoules et al., 2013). Similarly, automated feature tracking on optical imagery is often limited to horizontal movements (Roering et al., 2015). Furthermore, many remote sensing techniques are ineffective in vegetated regions, making bare Earth topographic models generated from repeat airborne lidar uniquely suited to high-resolution, remote landslide monitoring in forested environments.

Repeat topographic data have highlighted details of landslide kinematics (Corsini et al., 2007; Stumpf et al., 2015; Ventura et al., 2011), but these data are rarely capitalized on to infer landslide dynamics. Vertical changes or horizontal displacements can provide information about sediment budgets (DeLong et al., 2012), but three-dimensional (3-D) surface changes are generally needed to quantitatively infer subsurface characteristics of a landslide, where frictional processes govern its motion (Aryal et al., 2015; Booth et al., 2013). Furthermore, obtaining complete coverage of a landslide's surface displacement field at high resolution can be challenging because of heterogeneous displacements and erosion or deposition, which inhibit automated feature tracking. Here, we overcome many of these challenges and report the 3-D surface displacement field for a transiently reactivated landslide with 1-m spatial resolution and decimeter precision, which allows us to infer the physical processes governing its motion.

\section{Study Site: Silt Creek Landslide, Oregon}

The Silt Creek Landslide is a 3.5-km long by 200 - to $900-\mathrm{m}$ wide composite landslide, where different movement types have occurred in different areas of the displaced mass (Cruden \& Varnes, 1996), located in the forested western Cascade Mountains, Oregon (Figure 1). The terrain there is highly dissected, with the main ridges capped by Miocene basalt flows, and highly altered tuffs and tuffacious volcaniclastics of Oligocene to Miocene age underlying the valleys (Walker \& Duncan, 1989). Large, deep-seated landslides with superimposed surficial mass wasting processes are common throughout the region and typically found in areas of highly altered volcaniclastic materials (Swanson \& Swanston, 1977).

The landslide's crown is at a 1,100-m high ridgeline underlain by altered tuffs, volcaniclastics, and columnar basalt that crops out in places along the steep-walled, amphitheater-shaped head of the landslide. The upper $1.5 \mathrm{~km}$ of the landslide is relatively steep, with an average slope of $17^{\circ}$, and consists of numerous slumped blocks, water-filled closed depressions, and debris flow deposits. At the lower end of this section, there is a $100-\mathrm{m}$ high internal scarp with a slope of $35^{\circ}$. The lower $2 \mathrm{~km}$ of the landslide is gentler, with an average slope of $6^{\circ}$, and consists of a narrow, elongated transport zone that transitions into a wider, bulbous toe protruding into Thomas Creek. Marginal gullies run along both sides of the transport zone and are coincident with the lateral boundaries of the toe. Silt Creek, for which the landslide is named, flows in the eastern gully, and its name implies a history of slope instability.

Aerial photograph reconnaissance shows that the head of the landslide has been intermittently active since at least the late 1990s with small debris flows. However, in 2014, two much larger debris flows occurred in the landslide's head (Figure 1a). The uppermost debris flow likely occurred before April 2014, as noted by local foresters, and that failure caused the head scarp of the landslide to retrogress by $300 \mathrm{~m}$, transferring debris from intact ground to the preexisting landslide. The lower debris flow occurred in late June 2014 and transferred material from the internal scarp to the upper part of the transport zone, depositing up to $10 \mathrm{~m}$ of debris over a 200-m $\times 400-\mathrm{m}$ area (Figure 1a). The previously dormant transport zone and toe reactivated at that time as a slow Earth slide (Cruden \& Varnes, 1996; Hungr et al., 2014), and the subsequent motion of that Earth slide is the focus of this study. In July 2014, we began monitoring its movement with ground-based surveys, a repeat aerial lidar flight, and terrestrial lidar scanning (TLS).

\section{Methods}

\subsection{Aerial Lidar Correlation}

Aerial lidar data from 9 October 2012 and 23 October 2015 bracket the reactivation of the transport zone and toe in 2014, and we used those data to derive a 1-m resolution, 3-D surface displacement field for the first 16 months following reactivation with the phase correlation technique (supporting information). Phase 


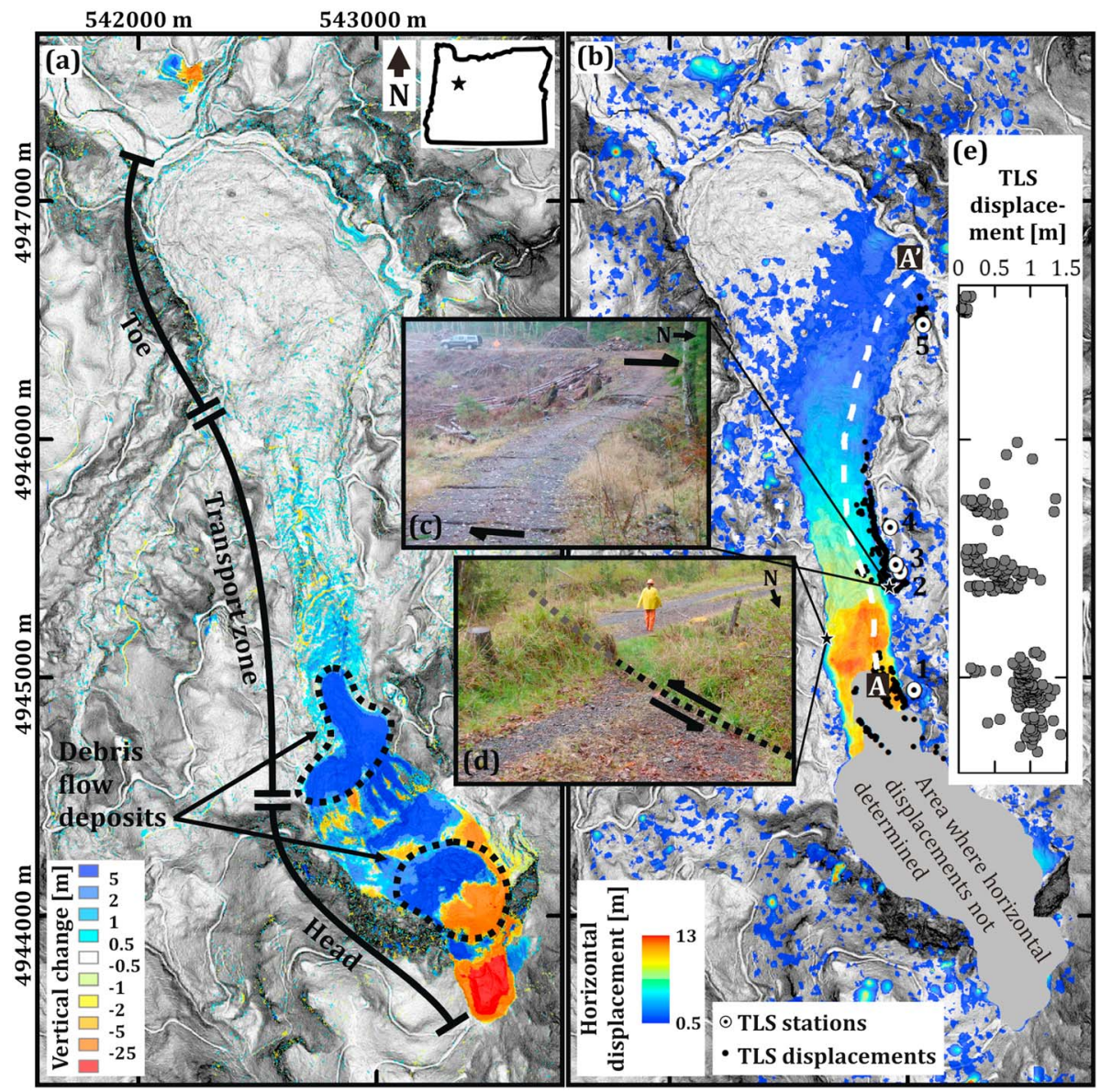

Figure 1. (a) Vertical changes and (b) horizontal displacements of the Silt Creek Landslide from repeat airborne lidar collected in October 2012 and October 2015. Areas of no color indicate changes or displacements below the minimum detectable difference. Main parts of the landslide, including the two debris flow deposits, are annotated in (a). In (b), black points indicate locations of displacements measured with TLS from November 2015 to October 2016, and bullseyes indicate scanner locations. Photographs (c) and (d) illustrate surface features of the wide eastern flank and narrow western flank. (e) Magnitude of horizontal displacements measured with TLS as a function of UTM Northing, vertically aligned to the map. TLS = terrestrial lidar scanning; UTM = Universal Transverse Mercator.

correlation calculates the correlation coefficient, $C$, as a function of relative offset, $(i, j)$, between two digital elevation models (DEMs), $z_{1}$ and $z_{2}$, as

$$
C(i, j)=F^{-1}\left(\frac{\mathbb{Z}_{1}\left(\omega_{x}, \omega_{y}\right) \mathbb{Z}_{2}^{*}\left(\omega_{x}, \omega_{y}\right)}{\left|\mathbb{Z}_{1}\left(\omega_{x}, \omega_{y}\right) \mathbb{Z}_{2}^{*}\left(\omega_{x}, \omega_{y}\right)\right|}\right),
$$

where $F^{-1}$ is the inverse Fourier transform, $\mathbb{Z}$ denotes the Fourier transform of $z, \omega_{x}$ and $\omega_{y}$ are frequencies in the $x$ and $y$ directions, respectively, the asterisk denotes the complex conjugate, and the vertical bars denote the magnitude (Brown, 1992; Heid \& Kääb, 2012; Kuglin, 1975; Leprince et al., 2007). The location of the peak in $C$ defines the relative displacement between $z_{1}$ and $z_{2}$, which has subpixel precision by interpolating $C$. We implemented equation (1) by modifying the program ImGRAFT (Messerli \& Grinsted, 2014; supporting information) and using a $65-\mathrm{m}$ patch size to correlate with the surrounding $97-\mathrm{m}$ wide search region. The minimum detectable displacement (MDD) with this technique was $0.5 \mathrm{~m}$, which we defined by calculating the standard deviation of apparent displacements of all pixels on stable ground. To extend the horizontal displacement field to 3-D, we subtracted the DEMs, documenting the local vertical elevation change at every grid cell, even where horizontal displacements were undefined (Avouac \& Leprince, 2015).

\subsection{Terrestrial Lidar Feature Tracking}

To extend the record of landslide displacements past the 2015 airborne lidar flight, we collected four sets of TLS data on 21 November 2015, 7 March 2016, 25 June 2016, and 8 October 2016. On each date we collected five scans along the eastern margin of the slow-moving, reactivated transport zone and toe using a FARO 
Focus $\times 330$. The scans had a point spacing of $3 \mathrm{~cm}$ at a typical distance of $100 \mathrm{~m}$ from the scanner to the landslide. Each scan from the first date was georeferenced, and subsequent scans were then precisely aligned (average root-mean-square error of $2 \mathrm{~cm}$ ) to the first scan using the iterative closest point algorithm (Besl \& Mckay, 1992) on only the stable parts of terrain. To measure displacements, we manually tracked tree trunks, stumps, and boulders that were imaged on each date. Based on apparent displacements of features on stable ground, the MDD with this technique was $3 \mathrm{~cm}$.

\section{Results}

\subsection{Spatial Pattern of Slip}

Phase correlation and vertical differencing of the airborne lidar DEMs documented two distinct patterns of landslide movement averaged over the time period October 2012 to October 2015 (Figure 1). At the landslide's head, erosion and deposition by the debris flows, combined with translation of the underlying landslide body, resulted in vertical elevation changes of -60 to $35 \mathrm{~m}$. These areas of erosion, deposition, and surface texture change prevented phase correlation from resolving horizontal displacements there. However, two 500-m long shear margins, visible in the 2015 lidar data and directly observed in the field, developed along both sides of the landslide's head, indicating horizontal translation.

In contrast to the spatially heterogeneous pattern of erosion, deposition, and deformation in the landslide's head, the transport zone and toe translated downslope as a relatively coherent mass after deposition of the lower debris flow (Figure 1b). Horizontal displacements were $13 \mathrm{~m}$ at the top of the transport zone and decreased gradually downslope to the MDD of $0.5 \mathrm{~m}$ at the landslide's toe. Along the flanks of the transport zone, the degree of shear strain localization varied with location. On the east flank, displacements changed gradually over $\sim 50 \mathrm{~m}$, consistent with observations of distributed shear accommodated on small surface cracks with offsets of centimeters to decimeters there (Figure 1c). On the west flank, displacements dropped abruptly from 6-8 to 0 m over a distance of just several meters, identifying the narrow shear margin there, where offset was accommodated across a single strike-slip structure (Figure 1d). Only the eastern side of the landslide's toe showed detectable displacements that dropped abruptly from 0.5 to $0 \mathrm{~m}$ at Thomas Creek.

The upper part of the transport zone, just downslope from the lower debris flow deposit, experienced $\sim 2 \mathrm{~m}$ of positive vertical change over a broad area, and the amount of vertical change gradually decreased downslope, to within the limit of detection across most of the lower transport zone and toe. Translation of small surface roughness elements, such as landslide hummocks and roads, and erosion or deposition in gullies generated localized areas of vertical change up to $\pm 3 \mathrm{~m}$ superimposed on the broad pattern of surface uplift.

Displacements of the transport zone and toe from November 2015 to October 2016, measured with TLS following the airborne lidar surveys, were smaller and similarly decreased in magnitude with downslope distance (Figures $1 \mathrm{~b}$ and 1e). Additional displacements over those 11 months decreased gradually from $1.5 \mathrm{~m}$ at the top of the transport zone to $4 \mathrm{~cm}$ at the distal end of the toe. In the upper part of the transport zone (TLS station 1), displacements were relatively constant in the cross-landslide direction and dropped abruptly to zero where a well-defined, narrow shear margin was present. In the middle of the transport zone (TLS stations 2-4), displacements were highest near the middle of the landslide and gradually decreased in magnitude with proximity to the flank, as also documented with the repeat airborne lidar.

\subsection{Temporal Pattern of Slip}

To document how surface displacements of the transport zone and toe evolved with time after the 2014 debris flows, we combined field measurements with the airborne and terrestrial lidar-derived displacements at two representative locations where a road crosses the upper part of the transport zone near TLS station 2 (Figures $1 \mathrm{~b}$ and 2). On the eastern margin, field surveys beginning 22 July 2014 indicated that the ground was disturbed, but no measureable horizontal displacements occurred through 25 November 2014. After that, horizontal velocity, measured with airborne lidar, increased to $0.45 \mathrm{~m} / \mathrm{month}$ averaged over the next 11 months then decreased smoothly to become unmeasurable with TLS by 8 October 2016 . On the western margin, the average velocity of the transport zone decreased from an initial high of $0.6 \mathrm{~m} / \mathrm{mon}$ th to $0.1 \mathrm{~m} / \mathrm{month}$ from 22 July to 25 November 2014, as measured in the field. After that, velocity increased to $0.7 \mathrm{~m} / \mathrm{month}$ averaged over the following 11 months. That location was not monitored with TLS, but by fall, 2016, movement had likely ceased there as it had throughout the rest of the transport zone and toe. 


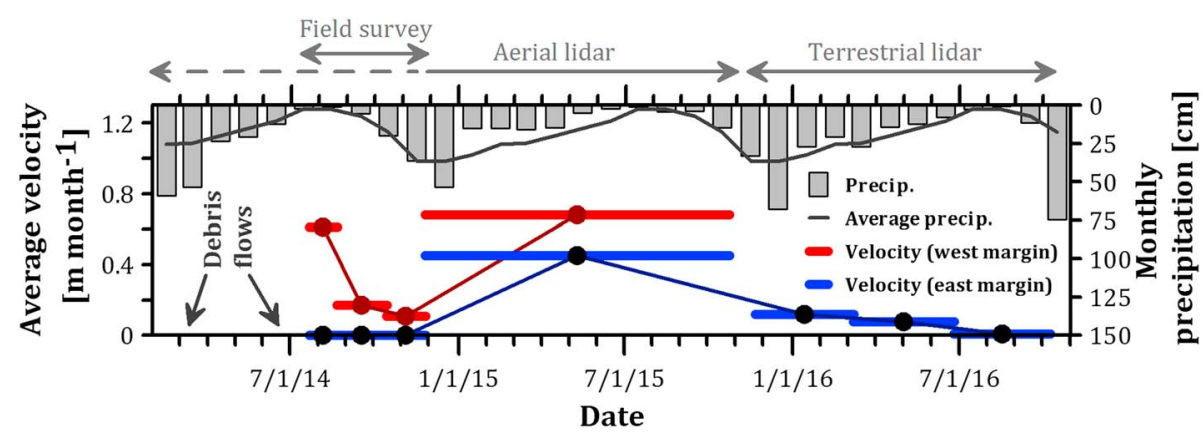

Figure 2. Monthly precipitation and landslide velocity from 2014 to 2016 measured in the field, with repeat airborne lidar and with repeat TLS at two representative locations (stars and photographs in Figure 1b), on the west (red) and east (blue) flanks of the transport zone. Widths of horizontal bars are the time spans over which velocity was averaged. Monthly precipitation is from the Detroit Dam weather station, located $\sim 20 \mathrm{~km}$ to the east at a comparable elevation. TLS $=$ terrestrial lidar scanning.

Monthly precipitation during the study period did not correlate with movement of the landslide's transport zone (Figure 2). While the 2014 debris flows occurred following two consecutive months with more than double the average precipitation, the transport zone did not reactivate at that time and instead moved fastest during an exceptionally dry period. From January to November 2015, monthly precipitation totaled $65 \%$ of average, and precipitation during all months except August, in which just $4.3 \mathrm{~cm}$ of rain fell, was below average. After that, the transport zone slowed and stopped during a period of average precipitation that also included the highest monthly total of the study period with $67.8 \mathrm{~cm}$ of precipitation in December 2015 .

\section{Interpretation}

Based on the detailed spatiotemporal evolution of surface displacements, we now determine whether undrained loading by the debris flows in the landslide's head was sufficient to reactivate the transport zone and toe. We then interpret the mechanisms that controlled movement of the transport zone and toe following reactivation, drawing on concepts from elastic fracture mechanics.

Both the 2014 debris flows deposited $\sim 10 \mathrm{~m}$ of sediment on the underlying landslide. This loading likely took place under undrained conditions, as commonly found in slow-moving landslides and indicated by our observations of ponded water and saturated ground throughout the landslide. For undrained conditions, an increase in normal stress due to an added surface load causes an equal, transient increase in pore pressure at the incipient slip surface, so the effective normal stress does not change there (Hutchinson \& Bhandari, 1971). Our qualitative field observations of increased artesian flow from springs downslope from the debris deposits further support the interpretation that undrained loading transiently increased pore pressures. Since effective normal stress does not change during undrained loading, the shear strength is a constant value, commonly referred to as the undrained cohesion in unconsolidated-undrained laboratory strength tests (Skempton, 1948). However, driving shear stress increases in proportion to the thickness of the additional load, pushing the underlying landslide toward failure. We estimated that loading by the debris flow deposits increased the driving shear stress from 10 to $20 \mathrm{kPa}$ (supplementary information), and it therefore is likely that undrained loading by either debris flow was sufficient to trigger reactivation of the underlying landslide.

The debris flow deposits were 300- to 400-m long in the downslope direction, which provides an estimate of the initial slip surface length that was reactivated at either undrained loading site. We now draw on concepts from linear elastic fracture mechanics and view the reactivation process as a shear fracture phenomenon (Martel, 2004) to infer how shear strength of the transport zone and toe evolved with slip following reactivation. Most landslide slip surfaces weaken with slip from a peak to residual coefficient of friction over a distance on the order of centimeters (Bishop et al., 1971). The magnitude of that drop divided by the slip over which it occurs is defined as the slip weakening rate (Palmer \& Rice, 1973). As a slip surface grows in length, its coefficient of friction drops toward the residual value, and the fracture may attain a critical length at which propagation will continue dynamically without additional forcing. For a shear fracture that is shallowly buried and parallel to the surface, that critical nucleation length, $\ell_{c}$, is 


$$
\ell_{c} \approx 4.4 \sqrt{\frac{\mu^{*} \tan \varphi}{w \gamma \sin \theta}},
$$

where $\varphi$ is the angle of internal friction, $w$ is the slip weakening rate, $\gamma$ is the unit weight of landslide material, $\theta$ is the slip surface angle with respect to horizontal, and $\mu^{*}=\mu /(1-v)$, where $\mu$ is the shear modulus, and $v$ is the Poisson ratio (Viesca \& Rice, 2012). Fracture propagation occurs because displacement across the growing slip surface increases shear stress downslope of the fracture tip, and once $\ell_{c}$ is exceeded, the fracture grows rapidly at the shear wave velocity. For subaerial landslides, the critical nucleation length is generally of order $10^{0}-10^{2} \mathrm{~m}$ and possibly up to $10^{4} \mathrm{~m}$ if rate-and-state friction is taken into account (Handwerger et al., 2016; Viesca \& Rice, 2012).

We estimated that $\ell_{c}=46-185 \mathrm{~m}$ for the Silt Creek Landslide, assuming a range of plausible shear moduli, such that $\mu^{*}=15-150 \mathrm{MPa}$, a typical weakening rate of $w=15 \mathrm{~m}^{-1}$ (Viesca \& Rice, 2012), a typical soil unit weight of $\gamma=20 \mathrm{kN} / \mathrm{m}^{3}$, the measured slope angle of $\theta=6^{\circ}$, and an estimated minimum angle of internal friction of $\varphi=12^{\circ}$ based on standard back analysis (supporting information). The main sources of uncertainty on this estimate are $\mu^{*}$ and $w$, which were not measured at the site and may vary by an order of magnitude or more for different landslide materials. Nonetheless, since $\varphi, \gamma$, and $\theta$ are well constrained, this estimate of $\ell_{c}$ should be the correct order of magnitude. Therefore, the initial slip surface length was likely greater than the critical nucleation length, suggesting that slip should have propagated dynamically. Instead, slip propagated gradually downslope over the following months, indicating that a strengthening mechanism must have been engaged at larger slip to inhibit dynamic rupture. Specifically, based on the timing of debris flow loading, the head of the landslide likely began to slip first, by April 2014, while the transport zone began to slip later, by July 2014, when we made our first field measurements. At that time, only the uppermost part of the transport zone (location of Figure 1d) had measurably translated downslope. This suggests that slip triggered by the lower debris flow initially propagated just 200-300 $\mathrm{m}$ in the downslope direction and that the main episode of transport zone and toe displacement was delayed by at least 6 months (Figure 2).

Two effects of pore pressure at the slip surface likely contributed to inhibiting dynamic rupture and slowing the downslope propagation of slip. First, low effective normal stress due to high pore pressure can increase the critical nucleation length (Dieterich, 1979), and such conditions were likely during the initial phase of reactivation by undrained loading. Second, a negative dilatancy-pore pressure feedback can slow fracture propagation (Liu \& Rubin, 2010; Segall et al., 2010) and is thought to regulate landslide motion (Iverson, 2005; Moore \& Iverson, 2002; Schulz, McKenna, et al., 2009). We next analyze the pattern of slip over the 2 years following reactivation to estimate the spatial pattern of shear strength change averaged over that time period.

We consider the longitudinal profile $A A^{\prime}$ (Figure $1 \mathrm{~b}$ ) and approximate the landslide as a deformable 1-D column inclined parallel to the surface slope along this profile (Figure 3a). The initial slip beneath the debris flow deposits, as well as downslope translation of the landslide's head, would have imparted an additional longitudinal stress in the downslope direction to the transport zone and toe, which we include in the force balance on an infinitesimal section of the transport zone (Figure 3a). To relate stress to displacement along the profile, we assume that stresses were transmitted elastically under quasi-static conditions, such that shear strength of the failure plane balanced driving stress during motion. The assumption of elastic stress transmission is justified for the toe and most of the transport zone of the landslide where calculated volumetric strain was small but not for the uppermost part of the transport zone, where a localized region of the landslide experienced large volumetric dilation of $10-20 \%$ (supporting information). That region was confined to the area just downslope from the lower debris flow deposit, and permanent deformation of that material could have reduced the magnitude of the stress that was transmitted downslope. With those assumptions, the change in shear strength, $\tau_{r}$, of the slip surface as a function of displacement is

$$
\tau_{r}-\tau=h E \frac{\mathrm{d}^{2} u}{\mathrm{~d} x^{2}}
$$

where $\tau$ is the gravitational driving shear stress, $h$ is landslide thickness, $E$ is Young's modulus, and $u$ is the displacement in the downslope direction (Puzrin \& Germanovich, 2005; Viesca, 2016). A convex-up displacement profile implies an increase in shear strength above the background gravitational shear stress, and vice versa. 


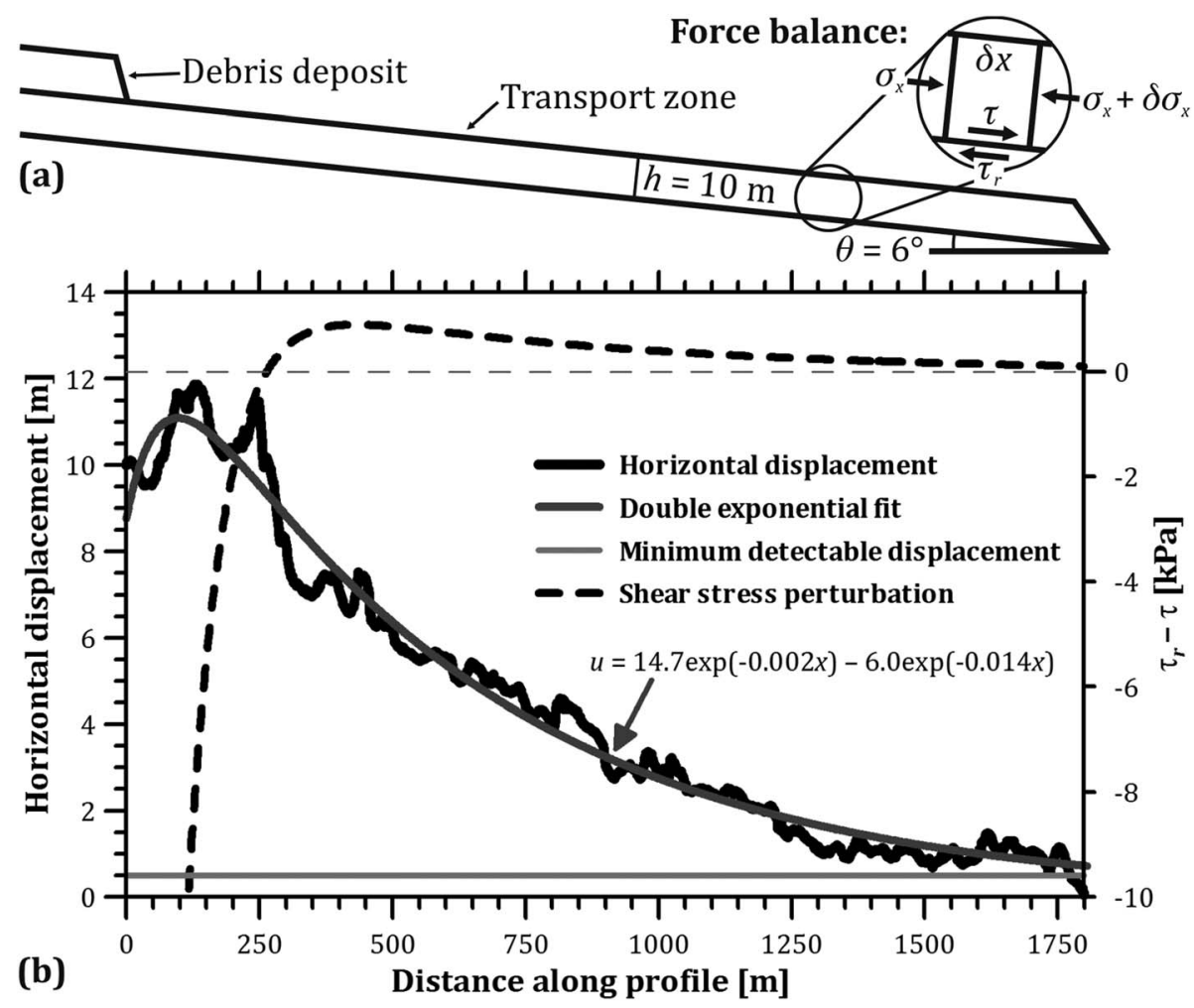

Figure 3. (a) Schematic diagram illustrating the idealized landslide profile used to interpret the observed displacement field, including the force balance on an infinitesimal element of the transport zone. (b) Horizontal displacement and calculated shear strength change along profile $\mathrm{AA}^{\prime}$ on Figure $1 \mathrm{~b}$.

After fitting a double exponential function to the displacement profile to smooth small-scale variability, we calculated the change in shear strength with $E=5 \mathrm{MPa}$ (Schulz, McKenna, et al., 2009) as a function of distance along profile $A A^{\prime}$ (Figure 3b). For the first $250 \mathrm{~m}$, the displacement profile is convex-up, and the calculated shear strength there dropped. Since that part of the profile experienced large volumetric strain, the assumption that stresses were transmitted purely elastically is not valid, and permanent deformation likely reduced the magnitude of the longitudinal stress that propagated downslope. However, from 250 to $1,800 \mathrm{~m}$, where the elastic assumption is valid, the displacement profile is concave-up, indicating an increase in shear strength that decays with downslope distance from a maximum value of $1 \mathrm{kPa}$. Assuming a different landslide thickness or Young's modulus would affect the magnitude of this strength increase, but the convexup displacement profile requires an increase in strength. Subtle strengthening of the slip surface was therefore sufficient to balance the additional longitudinal stress and allowed the transport zone and toe to stop moving after 2 years.

We infer that dilatant strengthening due to the negative pore pressure feedback is the most likely mechanism responsible for increasing shear strength. Hydraulic diffusivities for slow-moving landslides may be of order $10^{-6} \mathrm{~m}^{2} / \mathrm{s}$ (Iverson \& Major, 1987), so the timescale for pore pressure diffusion through the $\sim 10-\mathrm{m}$ thick landslide is on the order of years, consistent with the timing of landslide deceleration. Furthermore, the $2 \mathrm{~m}$ of surface uplift and dilation of $10-20 \%$ recorded with airborne lidar at the upper part of the transport zone provides direct evidence that dilation occurred there. The dilatancy-pore pressure feedback can operate at the grain scale as individual particles in the landslide shear zone move past one another and at much larger scales as landslide material deforms around roughness elements on its basal sliding surface (Baum \& Johnson, 1993; Iverson, 2005; Schulz, McKenna, et al., 2009). Since grain-scale dilatancy in a narrow shear zone becomes ineffective after a few centimeters of accumulated slip in laboratory samples (Moore \& Iverson, 2002), we infer that dilation of landslide material distributed throughout its thickness, especially as it deformed around large-scale roughness elements on the slip surface, was the most plausible mechanism for the shear strength increase. 


\section{Discussion and Conclusions}

Beyond the 2-year time span of the study, our results can more broadly inform our understanding of how large landslides evolve over the long term. Many slow-moving landslides move seasonally once a cumulative precipitation threshold is reached, and erosion of their toes creates space to accommodate continued movement (Iverson \& Major, 1987; Keefer \& Johnson, 1983; Kelsey, 1978). However, at our study site, the landslide's transport zone and toe had been stationary for decades before reactivating in response to an internal mass redistribution, rather than external environmental conditions, during an exceptionally dry period. Estimating landslide hazard or sediment delivery to channels under different climatic scenarios may therefore be challenging when landslide movement is dominated by internal dynamics rather than external forcing.

Furthermore, movement of the Silt Creek Landslide was driven in a top-down manner by processes occurring in its head, rather than in a bottom-up manner by processes perturbing its toe. We suspect that this reactivation mechanism may be common for mature landslides that have achieved gentle surface slopes by accumulating large amounts of slip. Hydrostatic pore pressures may therefore be insufficient to trigger further movement, and the transfer of fresh debris from steeper slopes at a landslide's crown to its gently sloping body is a documented process that can elevate pore pressures above hydrostatic, causing landslides to advance (Hutchinson \& Bhandari, 1971). In this manner, a mature landslide can continue to deliver sediment to a channel even after standard limit equilibrium analysis would predict it to be stable. Deformation of the landside body caused by top-down reactivation may also enhance erosion in gullies incised into its surface, which are an important source of sediment exported by many slow-moving landslides (Kelsey, 1978; Roering et al., 2009). Therefore, over geologic time, reactivation of large, mature landslides may be supply limited in the sense that the frequency and magnitude of localized slope failures in the landslide's head control its advancement downslope (Mackey \& Roering, 2011). Continued repeat lidar data acquisitions at yearly to decadal timescales should enable such landslides to be effectively monitored to determine the primary controls on their motion for hazard estimation and for deciphering their long-term behavior.

Acknowledgments

The authors thank George Hilley and an anonymous reviewer for comments that improved the quality of the manuscript Weyerhaeuser Company for access to the field site and airborne lidar data acquisition, and PSU student field assistants. McCarley was supported by a GSA student grant. Airborne lidar data are available through the Oregon Lidar Consortium (http://www.oregongeology.org/lidar/).

\section{References}

Allison, R. J., \& Brunsden, D. (1990). Some mudslide movement patterns. Earth Surface Processes and Landforms, 15(4), 297-311. https://doi. org/10.1002/esp.3290150402

Aryal, A., Brooks, B. A., \& Reid, M. E. (2015). Landslide subsurface slip geometry inferred from 3-D surface displacement fields. Geophysical Research Letters, 42, 1411-1417. https://doi.org/10.1002/2014GL062688

Avouac, J. P., \& Leprince, S. (2015). Geodetic imaging using optical systems. In G. Schubert (Ed.), Treatise on geophysics (2nd ed., pp. 387-424). Oxford: Elsevier. https://doi.org/10.1016/B978-0-444-53802-4.00067-1

Baum, R. L., \& Johnson, A. M. (1993). Steady movement of landslides in fine-grained soils-A model for sliding over an irregular slip surface, U. S. Geological Survey Bulletin 1842.

Bennett, G. L., Roering, J. J., Mackey, B. H., Handwerger, A. L., Schmidt, D. A., \& Guillod, B. P. (2016). Historic drought puts the brakes on earthflows in Northern California. Geophysical Research Letters, 43, 5725-5731. https://doi.org/10.1002/2016GL068378

Besl, P. J., \& Mckay, N. D. (1992). A method for registration of 3-D shapes. IEEE Transactions on Pattern Analysis and Machine Intelligence, 14(2), 239-256. https://doi.org/10.1109/34.121791

Bishop, A. W., Green, G. E., Garga, V. K., Andresen, A., \& Brown, J. D. (1971). A new ring shear apparatus and its application to the measurement of residual strength. Geotechnique, 21(4), 273-328. https://doi.org/10.1680/geot.1971.21.4.273

Booth, A. M., Lamb, M. P., Avouac, J.-P., \& Delacourt, C. (2013). Landslide velocity, thickness, and rheology from remote sensing: La Clapière landslide, France. Geophysical Research Letters, 40, 4299-4304. https://doi.org/10.1002/grl.50828

Bovis, M. J., \& Jones, P. (1992). Holocene history of earthflow mass movements in south-central British Columbia: The influence of hydroclimatic changes. Canadian Journal of Earth Sciences, 29(8), 1746-1755. https://doi.org/10.1139/E92-137

Brown, L. G. (1992). A survey of image registration techniques. Computing Surveys, 24(4), 325-376. https://doi.org/10.1145/146370.146374

Corsini, A., Borgatti, L., Coren, F., \& Vellico, M. (2007). Use of multitemporal airborne lidar surveys to analyse post-failure behaviour of earth slides. Canadian Journal of Remote Sensing, 33(2), 116-120. https://doi.org/10.5589/m07-015

Cruden, D. M., \& Varnes, D. J. (1996). Landslides: Investigation and mitigation. Chapter 3-Landslide types and processes, Transportation research board special report (247)

Daehne, A., \& Corsini, A. (2013). Kinematics of active earthflows revealed by digital image correlation and DEM subtraction techniques applied to multi-temporal LiDAR data. Earth Surface Processes and Landforms, 38(6), 640-654. https://doi.org/10.1002/esp.3351

Delbridge, B. G., Bürgmann, R., Fielding, E., Hensley, S., \& Schulz, W. H. (2016). 3D surface deformation derived from airborne interferometric UAVSAR: Application to the Slumgullion Landslide. Journal of Geophysical Research: Solid Earth, 121, 3951-3977. https://doi.org/10.1002/ 2015JB012559

DeLong, S. B., Prentice, C. S., Hilley, G. E., \& Ebert, Y. (2012). Multitemporal ALSM change detection, sediment delivery, and process mapping at an active earthflow. Earth Surface Processes and Landforms, 37(3), 262-272. https://doi.org/10.1002/esp.2234

Dieterich, J. H. (1979). Modeling of rock friction: 1. Experimental results and constitutive equations. Journal of Geophysical Research, 84(B5), 2161-2168. https://doi.org/10.1029/JB084iB05p02161

Handwerger, A. L., Rempel, A. W., Skarbek, R. M., Roering, J. J., \& Hilley, G. E. (2016). Rate-weakening friction characterizes both slow sliding and catastrophic failure of landslides. Proceedings of the National Academy of Sciences of the United States of America, 113(37), 10,281-10,286. https://doi.org/10.1073/pnas.1607009113 
Heid, T., \& Kääb, A. (2012). Evaluation of existing image matching methods for deriving glacier surface displacements globally from optical satellite imagery. Remote Sensing of Environment, 118, 339-355. https://doi.org/10.1016/j.rse.2011.11.024

Hu, J., Li, Z. W., Ding, X. L., Zhu, J. J., Zhang, L., \& Sun, Q. (2014). Resolving three-dimensional surface displacements from InSAR measurements: A review. Earth-Science Reviews, 133, 1-17. https://doi.org/10.1016/j.earscirev.2014.02.005

Hungr, O., Leroueil, S., \& Picarelli, L. (2014). The Varnes classification of landslide types, an update. Landslides, 11(2), 167-194. https://doi.org/ 10.1007/s10346-013-0436-y

Hutchinson, J. N., \& Bhandari, R. K. (1971). Undrained loading, a fundamental mechanism of mudflows and other mass movements. Geotechnique, 21(4), 353-358. https://doi.org/10.1680/geot.1971.21.4.353

Iverson, R. M. (2005). Regulation of landslide motion by dilatancy and pore pressure feedback. Journal of Geophysical Research, 110 , F02015. https://doi.org/10.1029/2004JF000268

Iverson, R. M., \& Major, J. J. (1987). Rainfall, ground-water flow, and seasonal movement at Minor Creek landslide, northwestern California: Physical interpretation of empirical relations. Geological Society of America Bulletin, 99(4), 579-594. https://doi.org/10.1130/00167606(1987)99\%3C579:RGFASM\%3E2.0.CO;2

Keefer, D. K., \& Johnson, A. M. (1983). Earth flows: Morphology, mobilization, and movement, Geological Survey Professional Paper, 1264. Kelsey, H. M. (1978). Earthflows in Franciscan Melange, Van Duzen River Basin, California. Geology, 6(6), 361-364. https://doi.org/10.1130/ 0091-7613(1978)6\%3C361:Eifmvd\%3E2.0.Co;2

Kuglin, C. (1975). The phase correlation image alignment method. Paper presented at Proc. IEEE International Conference on Cybernetics and Society, 1975

Leprince, S., Barbot, S., Ayoub, F., \& Avouac, J. P. (2007). Automatic and precise orthorectification, coregistration, and subpixel correlation of satellite images, application to ground deformation measurements. IEEE Transactions on Geoscience and Remote Sensing, 45(6), 1529-1558. https://doi.org/10.1109/Tgrs.2006.888937

Liu, Y., \& Rubin, A. M. (2010). Role of fault gouge dilatancy on aseismic deformation transients. Journal of Geophysical Research, 115, B10414. https://doi.org/10.1029/2010JB007522

Mackey, B. H., \& Roering, J. J. (2011). Sediment yield, spatial characteristics, and the long-term evolution of active earthflows determined from airborne LiDAR and historical aerial photographs, Eel River, California. Geological Society of America Bulletin, 123(7-8), 1560-1576. https:// doi.org/10.1130/B30306.1

Martel, S. J. (2004). Mechanics of landslide initiation as a shear fracture phenomenon. Marine Geology, 203(3-4), 319-339. https://doi.org/ $10.1016 / \mathrm{s} 0025-3227(03) 00313-x$

Massey, C. I., Petley, D. N., \& McSaveney, M. J. (2013). Patterns of movement in reactivated landslides. Engineering Geology, 159, 1-19. https:// doi.org/10.1016/j.enggeo.2013.03.011

Messerli, A., \& Grinsted, A. (2014). Image georectification and feature tracking toolbox: ImGRAFT. Geoscientific Instrumentation, Methods and Data Systems Discussions, 4(2), 491-513.

Moore, P. L., \& Iverson, N. R. (2002). Slow episodic shear of granular materials regulated by dilatant strengthening. Geology, 30(9), 843. https:// doi.org/10.1130/0091-7613(2002)030\%3C0843:sesogm\%3E2.0.co;2

Palmer, A. C., \& Rice, J. R. (1973). The growth of slip surfaces in the progressive failure of over-consolidated clay. Proceeding of the Royal Society of London, 332(1591), 527-548. https://doi.org/10.1098/rspa.1973.0040

Puzrin, A. M., \& Germanovich, L. N. (2005). The growth of shear bands in the catastrophic failure of soils. Proceedings of the Royal Society A: Mathematical, Physical and Engineering Sciences, 461(2056), 1199-1228. https://doi.org/10.1098/rspa.2004.1378

Raucoules, D., de Michele, M., Malet, J. P., \& Ulrich, P. (2013). Time-variable 3D ground displacements from high-resolution synthetic aperture $\operatorname{radar}($ SAR). Application to La Valette landslide (South French Alps). Remote Sensing of Environment, 139, 198-204. https://doi.org/10.1016/ j.rse.2013.08.006

Roering, J. J., Mackey, B. H., Handwerger, A. L., Booth, A. M., Schmidt, D. A., Bennett, G. L., \& Cerovski-Darriau, C. (2015). Beyond the angle of repose: A review and synthesis of landslide processes in response to rapid uplift, Eel River, Northern California. Geomorphology, 236, 109-131. https://doi.org/10.1016/j.geomorph.2015.02.013

Roering, J. J., Stimely, L. L., Mackey, B. H., \& Schmidt, D. A. (2009). Using DInSAR, airborne LiDAR, and archival air photos to quantify landsliding and sediment transport. Geophysical Research Letters, 36, L19402. https://doi.org/10.1029/2009GL040374

Scheingross, J. S., Minchew, B. M., Mackey, B. H., Simons, M., Lamb, M. P., \& Hensley, S. (2013). Fault-zone controls on the spatial distribution of slow-moving landslides. Geological Society of America Bulletin, 125(3-4), 473-489. https://doi.org/10.1130/b30719.1

Schulz, W. H., Kean, J. W., \& Wang, G. (2009). Landslide movement in southwest Colorado triggered by atmospheric tides. Nature Geoscience, 2(12), 863-866. https://doi.org/10.1038/ngeo659

Schulz, W. H., McKenna, J. P., Kibler, J. D., \& Biavati, G. (2009). Relations between hydrology and velocity of a continuously moving landslideEvidence of pore-pressure feedback regulating landslide motion? Landslides, 6(3), 181-190. https://doi.org/10.1007/s10346-009-0157-4

Segall, P., Rubin, A. M., Bradley, A. M., \& Rice, J. R. (2010). Dilatant strengthening as a mechanism for slow slip events. Journal of Geophysical Research, 115, B12305. https://doi.org/10.1029/2010JB007449

Skempton (1948). A study of the geotechnical properties of some post-glacial clays. Geotechnique, 1, 7-22.

Stumpf, A., Malet, J. P., Allemand, P., Pierrot-Deseilligny, M., \& Skupinski, G. (2015). Ground-based multi-view photogrammetry for the monitoring of landslide deformation and erosion. Geomorphology, 231, 130-145. https://doi.org/10.1016/j.geomorph.2014.10.039

Swanson, F. J., \& Swanston, D. N. (1977). Complex mass-movement terrains in the western Cascade Range, Oregon. Reviews in Engineering Geology, III, 113-124.

Ventura, G., Vilardo, G., Terranova, C., \& Sessa, E. B. (2011). Tracking and evolution of complex active landslides by multi-temporal airborne LiDAR data: The Montaguto landslide (Southern Italy). Remote Sensing of Environment, 115(12), 3237-3248. https://doi.org/10.1016/j. rse.2011.07.007

Viesca, R. C. (2016). Stable and unstable development of an interfacial sliding instability. Physical Review E, 93(6), 060202. https://doi.org/ 10.1103/PhysRevE.93.060202

Viesca, R. C., \& Rice, J. R. (2012). Nucleation of slip-weakening rupture instability in landslides by localized increase of pore pressure. Journal of Geophysical Research, 117, B03104. https://doi.org/10.1029/2011JB008866

Walker, G. W., and Duncan, R. A. (1989). Geologic map of the Salem 1 degree x 2 degrees, quadrangle, western Oregon, U.S. Geological Survey. 